possibly be due to the variability that characterises asthma. Nevertheless, we believe that this study provides proof of concept for the use of an experimental virus infection model in the study of chronic asthmatics whose disease requires the use of ICS.

Experimental rhinovirus infection safely induces a mild asthma exacerbation in moderate asthmatics on inhaled steroids http://ow.ly/sN04P

Peter T. Adura ${ }^{1}$, Eleanor Reed ${ }^{2}$, Jonathan Macintyre ${ }^{3}$, Ajerico del Rosario ${ }^{3}$, James Roberts ${ }^{2}$, Rachel Pestridge ${ }^{2}$, Rona Beegan ${ }^{2}$, Christine B. Boxall ${ }^{2}$, Chang Xiao ${ }^{2}$, Tatiana Kebadze ${ }^{3}$, Juliya Aniscenko ${ }^{3}$, Victoria Cornelius ${ }^{1}$, James E. Gern ${ }^{4}$, Phillip D. Monk ${ }^{2}$, Sebastian L. Johnston ${ }^{3}$ and Ratko Djukanović ${ }^{1}$

${ }^{1}$ Clinical and Experimental Sciences, Southampton NIHR Respiratory Biomedical Research Unit, University of Southampton Faculty of Medicine, Southampton, ${ }^{2}$ Synairgen Research Ltd, Southampton, and ${ }^{3}$ National Heart and Lung Institute and Centre for Respiratory Infections, Imperial College, MRC and Asthma UK Centre in Allergic Mechanisms of Asthma, Imperial College NHS Trust NIHR Comprehensive Biomedical Research Centre, London, UK. ${ }^{4}$ University of Wisconsin School of Medicine and Public Health, Madison, WI, USA.

Correspondence: R. Djukanović, Clinical and Experimental Sciences, Southampton NIHR Respiratory Biomedical Research Unit, University of Southampton Faculty of Medicine, Mailpoint 810, Level F, Sir Henry Wellcome Laboratories, South Block, Southampton General Hospital, Southampton SO16 6YD, UK.

E-mail: r.djukanovic@soton.ac.uk

Received: Aug 132013 | Accepted after revision: Oct 012013 | First published online: Dec 052013

Support statement: This study was supported by a collaborative research grant from Synairgen plc (Southampton, UK).

Conflict of interest: Disclosures can be found alongside the online version of this article at www.erj.ersjournals.com

Acknowledgements: The authors wish to acknowledge all the staff, in particular the nurses, in the Southampton NIHR Biomedical Research Unit, the Southampton NIHR Wellcome Clinical Research Facility and the Imperial NIHR Comprehensive Biomedical Research Centre (all Southampton, UK) for their help with clinical aspects of the study, and the patient volunteers for donating their time and samples.

\title{
References
}

1 Johnston SL, Pattemore PK, Sanderson G, et al. The relationship between upper respiratory infections and hospital admissions for asthma: a time-trend analysis. Am J Respir Crit Care Med 1996; 154: 654-660.

2 Message SD, Laza-Stanca V, Mallia P, et al. Rhinovirus-induced lower respiratory illness is increased in asthma and related to virus load and Th1/2 cytokine and IL-10 production. Proc Natl Acad Sci USA 2008; 105: 13562-13567. Reddel H, Ware S, Marks G, et al. Differences between asthma exacerbations and poor asthma control. Lancet 1999; 353: 364-369.

4 Lemanske RF Jr, Dick EC, Swenson CA, et al. Rhinovirus upper respiratory infection increases airway hyperreactivity and late asthmatic reactions. J Clin Invest 1989; 83: 1-10.

5 Wark PA, Grissell T, Davies B, et al. Diversity in the bronchial epithelial cell response to infection with different rhinovirus strains. Respirology 2009; 14: 180-186.

6 DeMore JP, Weisshaar EH, Vrtis RF, et al. Similar colds in subjects with allergic asthma and nonatopic subjects after inoculation with rhinovirus-16. J Allergy Clin Immunol 2009; 124: 245-252.

Newman SP. Aerosol deposition considerations in inhalation therapy. Chest 1985; 88: Suppl. 2, 152S-160S.

8 Uller L, Leino M, Bedke N, et al. Double-stranded RNA induces disproportionate expression of thymic stromal lymphopoietin versus interferon-beta in bronchial epithelial cells from donors with asthma. Thorax 2010; 65: 626-632.

9 Kerstjens HA, Brand PL, de Jong PM, et al. Influence of treatment on peak expiratory flow and its relation to airway hyperresponsiveness and symptoms. The Dutch CNSLD Study Group. Thorax 1994; 49: 1109-1115.

10 Wark PA, Johnston SL, Bucchieri F, et al. Asthmatic bronchial epithelial cells have a deficient innate immune response to infection with rhinovirus. J Exp Med 2005; 201: 937-947.

\section{Relationship between leptin and lung function in young healthy children}

\author{
To the Editor:
}

Leptin, a product of the obese (ob) gene, was discovered as a hormone that plays a key role in regulating energy intake and expenditure. Over the past years, interest in the other functions of this pleiotropic hormone has increased. Leptin is primarily produced by adipocytes and is produced in lower amounts in 
other tissues. In the human lung, expression of leptin has been described in bronchial epithelial cells and alveolar macrophages [1]. Leptin receptors have a universal distribution that includes the respiratory system. The lung has mainly the Ob-Rb isoform, which is considered to be the fully functional receptor and most effective isoform [2]. Receptors have been identified in human bronchial and alveolar epithelial cells, bronchial smooth muscle cells, and bronchial submucosa [3]. The presence of these receptors together with evidence of local leptin production supports the concept that leptin may play a role in the regulation of airway diameter, lung development and the pathogenesis of respiratory diseases. The role of leptin in lung development has only been studied in animals and it is not known if these findings can be extended to the development of healthy human lungs. In this study we evaluated the relationship between plasma leptin levels and lung function in healthy young children and we assessed whether this relationship was modulated by the amount of adipose tissue deposits, the main source of leptin.

Participants in this study were children from the Wheezing Illness Study Leidsche Rijn (WHISTLER), an ongoing population-based birth cohort [4]. At the age of 8 years, participants were invited for a follow-up visit. During this visit, information on the child and parents was gathered by questionnaire and weight and height were measured. Spirometry was performed conforming to the latest American Thoracic Society/ European Respiratory Society statements. Intra-abdominal and subcutaneous fat were measured using ultrasound [5]. After an overnight fast, a blood sample was taken in a sodium-heparin tube. A multiplex adipokine immunoassay, Luminex (Bio-Rad, Munich, Germany), was used for determination of the concentration of leptin [6]. This study was approved by the Medical Ethical Committee of the University Medical Center Utrecht (the Netherlands). Written informed parental consent was obtained.

Differences in subject characteristics above and below median leptin levels were tested using independent ttest (continuous variables) and Chi-squared (frequencies). The relationship between leptin (independent variable) and lung function (dependent variable) was assessed using linear regression analysis. Using multivariable linear regression we adjusted for possible confounders. Missing data on determinants were imputed using multiple imputations. Pooled results of 10 imputed datasets are expressed as linear regression coefficients with $95 \%$ confidence intervals. Due to a skewed distribution of residuals in the regression model with leptin, we entered leptin into the model after natural log transformation. To test if modification by sex or weight was statistically significant we added an interaction term (product of the potential effect modifier and leptin) to the regression model. All analyses were performed with SPSS version 20.0 for windows (IBM, Armonk, USA).

In total, 138 8-year-olds had successful spirometry and measurement of leptin concentration in plasma. Mean \pm SD forced expiratory volume in $1 \mathrm{~s}$ (FEV1) of these children was $1.78 \pm 0.27 \mathrm{~L}$ and the median (interquartile range) leptin level was $5.07(1.80-7.40) \mathrm{ng} \cdot \mathrm{mL}^{-1}$. The children with lower leptin levels were older ( 8.3 versus 8.0 years; $\mathrm{p}<0.01)$, had a lower weight $(27.6$ versus $28.6 \mathrm{~kg} ; \mathrm{p}<0.01)$ and a smaller waist circumference $(57.5$ versus $59.3 \mathrm{~cm} ; \mathrm{p}=0.03)$ than children with higher levels of leptin. No significant differences were observed in exposure to environmental factors.

Without adjustments, leptin was negatively associated with FEV1. Figure 1 shows the FEV1 plotted against leptin levels. The linear regression coefficient $(95 \% \mathrm{CI})$ of the natural logarithm of leptin was $-0.06(-0.11-$ $-0.01) \mathrm{L} \cdot \mathrm{ng}^{-1} \cdot \mathrm{mL}$, which indicates that with a $10 \%$ increase in leptin, FEV1 decreases by $5.7 \mathrm{~mL}$ (i.e. by $\left.\ln (1.1) \times-0.06 \mathrm{~L} \cdot \mathrm{ng}^{-1} \cdot \mathrm{mL}\right)$. Adjustment for age and sex slightly attenuated the association to $-0.04(-0.09-$ $0.01) \mathrm{L} \cdot \mathrm{ng}^{-1} \cdot \mathrm{mL}$ and $-0.05(-0.10-0.00) \mathrm{L} \cdot \mathrm{ng}^{-1} \cdot \mathrm{mL}$, respectively, while adjustment for anthropometrics strengthened the association. After adjustment for weight, a $10 \%$ increase in leptin was associated with an $11.4 \mathrm{~mL}$ decrease in FEV1. After adjustment for intra-abdominal and subcutaneous fat the association between leptin and FEV1 was still present (linear regression coefficient (95\% CI) of -0.07 (-0.12-0.02) $\mathrm{L} \cdot \mathrm{ng}^{-1} \cdot \mathrm{mL}$ and $-0.10(-0.15--0.06) \mathrm{L} \cdot \mathrm{ng}^{-1} \cdot \mathrm{mL}$, respectively). The multivariable analyses with age, sex, weight and height and another model with breastfeeding, smoke exposure (during pregnancy and current), infections and allergies diagnosed by the general practitioner barely changed the linear regression coefficients of leptin compared with the univariable analysis. The regression analysis with forced vital capacity (FVC) as the dependent variable showed similar results. Weight and sex were not effect modifiers of the association ( $\mathrm{p}$-values for the interaction term of 0.28 and 0.96 , respectively).

Previous studies of the role of leptin in lung development were all carried out in animal models, which represents a major limitation in extrapolating the results to humans. Animal studies have shown that leptin is important for postnatal development of the lungs. Genetically obese, leptin deficient mice (ob/ob mice) exhibit significantly lower lung volume and lower alveolar surface area at 2 weeks of age, when compared with heterozygotes or control animals [7]. Other evidence in mice has shown that leptin increases airway diameter [8]. The parasympathetic nervous system signals in airway smooth muscle cells to cause bronchoconstriction. The study showed that leptin signalling outside the hypothalamus in cholinergic neurons inhibited parasympathetic signalling in airway smooth muscle cells, which led to bronchodilation. 
FIGURE 1 Forced expiratory volume in $1 \mathrm{~s}(\mathrm{FEV} 1)$ plotted against plasma leptin levels. The solid line is the regression line of the association between leptin and $\mathrm{FEV} 1$, dotted lines indicate $95 \%$ confidence intervals.

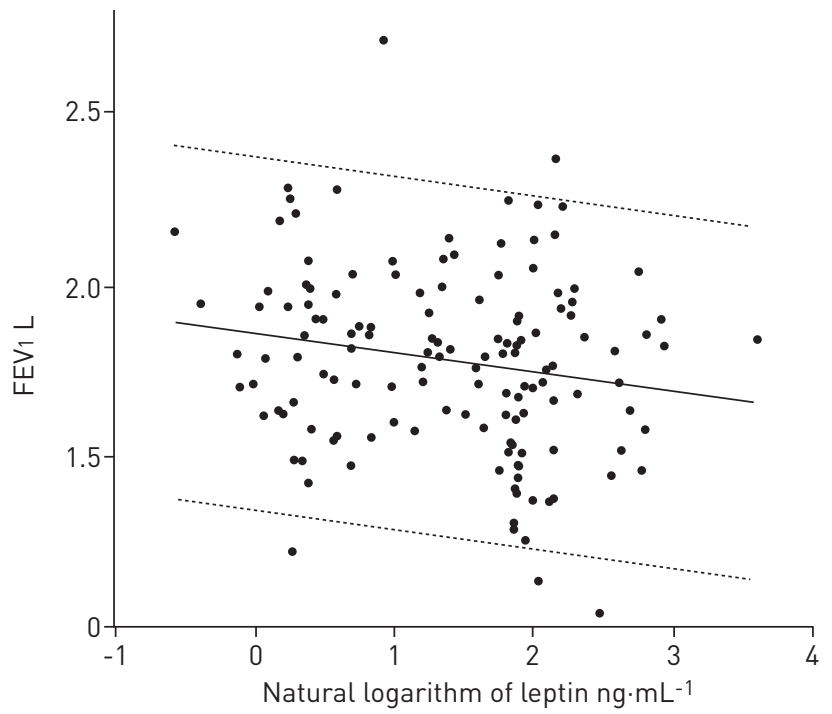

In obese mice, bronchoconstriction occurred through leptin resistance [8]. Based on this data from animal studies one might expect that in healthy (nonobese) individuals higher leptin would lead to a more favourable lung function. However, we could not confirm this in our study involving young children, in which we observed the opposite relationship. The differences could be due to differences in autonomic nervous system innervations. Furthermore, mouse studies often reflect a model with either lipodystrophic "fat-free" or diet-induced obese mice in which leptin levels are either very low or high, which is not comparable with fat mass or leptin levels in our healthy group of children.

The direction of our findings is compatible with other studies performed in humans. A study performed in mainly asthmatic children showed a negative correlation between leptin and FEV1 \% predicted and forced expiratory flow at 25-75\% of FVC [9]. A large population-based study assessed the same association and found similar results in nonobese adults [10]. In our study, weight was not an effect-modifier in the association between leptin and lung function. As only few of our children were overweight, clinical leptin resistance was probably not present, although leptin resistance may gradually increase with increasing fat mass.

A nested case-control study in rescue workers, following the terrorist attacks on September 11, 2001 in New York City, NY, USA, showed that leptin was an independent risk factor for greater susceptibility to FEV1 impairment. Leptin increased the odds of abnormal FEV1 by more than twofold after adjustment for body mass index [11]. This longitudinal study supports the hypothesis that leptin has a direct effect on the airways, making reverse causation less likely.

As our study has a cross-sectional design, only assumptions about causality of associations can be made. A longitudinal study could give us more insights into the development of the respiratory system and the role of leptin. We measured the children at the age of 8 years. It would be interesting to measure children from an earlier age onwards. However, the lung grows until late adolescence and recent research showed that even alveolarisation is ongoing throughout childhood and adolescence in humans [12].

In conclusion, this is the first study to show an association between higher leptin plasma concentration and lower lung function, independent of adipose tissue in healthy children. The fact that we see such a strong association in healthy children supports the hypothesis that leptin has a functional role in the respiratory system.

Higher plasma leptin level is associated with lower lung function, independent of adipose tissue in healthy children http://ow.ly/qOyUc

Jacobien B. Eising ${ }^{1}$, Cuno S.P.M. Uiterwaal ${ }^{2}$, Annemieke M.V. Evelein ${ }^{2}$, Frank L.J. Visseren ${ }^{3}$ and Cornelis K. van der Ent ${ }^{1}$ ${ }^{1}$ Dept of Paediatric Pulmonology, Wilhelmina Children's Hospital, University Medical Center Utrecht, Utrecht, ${ }^{2}$ Julius Center for Health Sciences and Primary Care, University Medical Center Utrecht, Utrecht, and ${ }^{3}$ Dept of Vascular Medicine, University Medical Center Utrecht, Utrecht, The Netherlands.

Correspondence: J.B. Eising, Paediatric Pulmonology Dept, Wilhelmina Children's Hospital, Room KH.01.419.0, Lundlaan 6, P.O. Box 85090, 3508 AB Utrecht, the Netherlands. E-mail: j.eising@umcutrecht.nl 
Support statement: The Wheezing Illnesses STudy LEidsche Rijn received grant 2100.0095 from The Netherlands Organisation for Health Research and Development (ZonMw). An unrestricted grant was received from GlaxoSmithKline. Additionally, this work was financially supported by the UMC Utrecht Vascular Prevention Project.

Conflict of interest: Disclosures can be found alongside the online version of this article at www.erj.ersjournals.com

Acknowledgements: The authors gratefully acknowledge all parents and children who participated, C. Geerts (Julius Center for Health Sciences and Primary Care, University Medical Center Utrecht, Utrecht, the Netherlands) and L. van der Feltz-Minkema (Dept of Paediatric Pulmonology, Wilhelmina Children's Hospital, University Medical Center Utrecht, Utrecht) for their major contribution to the data collection, M. Olling-de Kok (Dept of Paediatric Pulmonology, Wilhelmina Children's Hospital, University Medical Center Utrecht, Utrecht) for secretarial support, J. Zwerver (Julius Center for Health Sciences and Primary Care, University Medical Center Utrecht, Utrecht) for data management and the Vascular Imaging Centre for assistance in the vascular measurements.

\section{References}

1 Bruno A, Pace E, Chanez P, et al. Leptin and leptin receptor expression in asthma. J Allergy Clin Immunol 2009; 124 : 230-237.

2 Bergen HT, Cherlet TC, Manuel P, et al. Identification of leptin receptors in lung and isolated fetal type II cells. Am J Respir Cell Mol Biol 2002; 27: 71-77.

3 Nair P, Radford K, Fanat A, et al. The effects of leptin on airway smooth muscle responses. Am J Respir Cell Mol Biol 2008; 39: 475-481.

4 Katier N, Uiterwaal CSPM, de Jong BM, et al. The Wheezing Illnesses Study Leidsche Rijn (WHISTLER): rationale and design. Eur J Epidemiol 2004; 19: 895-903.

5 Evelein AMV, Visseren FLJ, van der Ent CK, et al. Excess early postnatal weight gain leads to increased abdominal fat in young children. Int J Pediatr 2012; 2012: 141656.

6 Schipper HS, de Jager W, van Dijk ME, et al. A multiplex immunoassay for human adipokine profiling. Clin Chem 2010; 56: 1320-1328.

7 Huang K, Rabold R, Abston E, et al. Effects of leptin deficiency on postnatal lung development in mice. J Appl Physiol (1985) 2008; 105: 249-259.

8 Arteaga-Solis E, Zee T, Emala CW, et al. Inhibition of leptin regulation of parasympathetic signaling as a cause of extreme body weight-associated asthma. Cell Metab 2013; 17: 35-48.

9 Kim KW, Shin YH, Lee KE, et al. Relationship between adipokines and manifestations of childhood asthma. Pediatr Allergy Immunol 2008; 19: 535-540.

10 Sin DD, Man SFP. Impaired lung function and serum leptin in men and women with normal body weight: a population based study. Thorax 2003; 58: 695-698.

11 Naveed B, Weiden MD, Kwon S, et al. Metabolic syndrome biomarkers predict lung function impairment: a nested case-control study. Am J Respir Crit Care Med, 185: 392-399.

12 Narayanan M, Owers-Bradley J, Beardsmore CS, et al. Alveolarization continues during childhood and adolescence: new evidence from helium-3 magnetic resonance. Am J Respir Crit Care Med 2012; 185: 186-191.

\section{The association between public transport and active tuberculosis in Lima, Peru}

To the Editor:

While there have been impressive gains in the global control of tuberculosis (TB) over the past two decades, TB remains a leading cause of death and efforts to decrease its burden have been limited by the rise of drug resistant strains [1]. As drug-resistant TB remains exceedingly difficult and costly to treat, more research is needed to identify areas for improving primary prevention of TB.

The risk of TB transmission is increased whenever there is overcrowding, poor ventilation and exposure to an infected individual, and public transport has been identified as a potential setting with increased risk for TB transmission [2]. Indeed, recent research demonstrates the fraction of rebreathed air on public transport is mathematically correlated with a higher risk of contracting TB [3].

Previous investigations using cross-sectional data in Lima, Peru, have demonstrated that community, rather than household, transmission may account for up to $70 \%$ of incident infections [4]. Studies conducted in Lima found an increased risk of TB infection among individuals who rode minibuses [5] and those who worked on public transport [6]. However, these studies were limited by misclassification of TB diagnosis, imprecise time variables and wide confidence intervals. 